\title{
Review on the Propagation Mode of China's Knowledge Web Celebrity from Gao Xiaosong in Focus On*
}

\author{
Lu Wang \\ Faculty of Arts and Sciences \\ Shanghai Polytechnic University \\ Shanghai, China 201209
}

\begin{abstract}
With the popularity of the Internet, the channels of content dissemination are increasingly diverse. With its convenience, rapidity and high efficiency, mobile audio has gradually become an important way of content transmission, from which a large number of knowledge web celebrity has been born. In this paper, Gao Xiaosong in Focus On on Dragonfly FM is taken as the research object, and the $5 \mathrm{~W}$ propagation mode of Lasswell is adopted for analysis to further analyze the propagation mode of knowledge web celebrity.
\end{abstract}

Keywords-knowledge web celebrity; Focus On; $5 W$ propagation mode

\section{INTRODUCTION}

Focus $O n$ is a paid audio program jointly produced by Dragonfly FM and Gao Xiaosong. Instead of teaching people how to manage money, read books or be successful, Gao Xiaosong is blatantly gossiping on the show. Unlike paid content, which is popular around the world, the show, with a touch of Roosevelt's fireside chat, seems to have tapped into a gap in the market and the response has been overwhelming. Compared with the serious expressions in traditional content dissemination, Focus On seems loose, casual and informal, and will not make the audience feel ashamed, self-reproach and other frustration, and the content is not stick to one pattern. The author explored the reasons for its success and found that the knowledge web celebrity, Gao Xiaosong in Focus On, has strong and unique communication advantages in many aspects. The maximum resultant force in propagation is formed under $5 \mathrm{~W}$ mode: Who, Says What, In Which Channel, To Whom, and With What Effect.

\section{COMMUNICATION SUBJECT}

The subject of communication is the communicator in the

*Fund: This paper is the research result of Shanghai Industrial University's Quality Curriculum Construction Project (code A01GY19G012-02); research results of the Public Relations Discipline Construction Project "New Media Public Relations Communication" of Shanghai Polytechnic University (discipline number: XXKPY 1610); and the achievement of the Special Plan for the Construction of the Teaching System of Curriculum Ideological and Political Education in Universities in Shanghai (code: A30DB191412-0214). process of communication, which can be an organization or an individual.

In the communication process of knowledge web celebrity, the subject of communication is usually an individual, that is, the communication of personal knowledge. The subject of communication of Focus On is personal brand, and Gao Xiaosong is a knowledge web celebrity with "individual" as the subject of communication. Gao Xiaosong is the communication subject of Focus On.

Personal communication is about personal brand image. Accordingly, more things need to be established and maintained than enterprises. Personal brand not only needs to grasp a certain characteristic to spread like enterprise brand communication, but also needs to show personal brand to consumers from various aspects to attract more audiences. Personal communication includes many contents such as specialty, dressing style, values and role positioning. Gao Xiaosong himself has multiple identities: a poet, a musician, a judge on variety shows, a talk show host, and a movie executive. As he puts it, "I'm more like a retainer, a busker, and the one who pays the highest price gets the ownership." Such friendly ridicule is what fans love.

\section{A. The Spread of Super IP}

Super IP, also known as super intellectual property, is an intellectual property with a high number of readers, viewers or fans and a certain social influence. Gao Xiaosong had many other types of shows about himself before the audio show Focus On. Among them, the one that leaves a deep impression on us is Let's Talk, the other is Morning Call created by iQIYI and himself. Gao Xiaosong has appeared many times in the public eye. Whether through TV shows or news events, his name is familiar to the public. Gao Xiaosong has become synonymous with "awkwardly adorable" in the eyes of some people, which has become his unique personal brand image in the hearts of the audience.

\section{B. Clear Style}

The problem that knowledge web celebrity must make clear above all is: What kind of communicator do they want to be? When they appear in the public eye at the very 
long-term vitality. When the temporary crazy is over, if there is no valuable content to carry and shape, there will be no differentiation and recognition. Focus On is essentially the sharing of content, so it needs the development of highquality content and the presentation of the program's personal style and charm, so as to attract users for a long time. Gao Xiaosong has written songs, played guitar, played music, published books, worked as a filmmaker and appeared in variety shows. His personal style is highly recognizable. He displays and interprets the content of many fields in a personal style of "awkwardly adorable", forming his own content label.

\section{COMmunication ChanNEL: MobILE AUdiO}

The dissemination of knowledge web celebrity is inseparable from the correct channel. If the channel type is divided, different audiences will be formed. These audiences have different media preferences and habits, which have a direct impact on the communication channels.

The audience that Gao Xiaosong faces is mostly young people of literature and art, who are keen on reading books, reading poems and chatting about ideals. After understanding the preference of the audience (For example, like nostalgia, radio, handwritten letters and so on), Gao Xiaosong's Focus On chose the more direct mobile audio as the transmission channel. Apart from the visual impact, the content is conveyed by the simple voice, which gives the audience a great space for free imagination. This is exactly the communication channel that the audience prefers to choose. As a paid audio column, Focus On has the advantage of being in the right place at the right time given the increasingly better mobile audio market. Data from mobile APP of iResearch shows that in March 2019, the downloads of mobile video far exceeded that of mobile audio, but in terms of sequential growth, mobile audio tends to rise while mobile video declines. This shows that the user has been gradually to get rid of their unnecessary visual fatigue.

Focus On spreads Gao Xiaosong's personal brand with the help of mobile audio, and spreads content to audience through sound. Today, when video and pictures are omnipresent, tedious visual transmission is eliminated, and the simplest and most direct discourse is used to communicate with the user, so that the user's attention is free and not restricted by the mobile screen. In the meantime, audio can bring infinite imagination space to the user. When Gao Xiaosong said a certain sentence or a certain story that made the audience feel empathy, it will be easier to establish an intimate relationship with the audience.

\section{THE AUdIENCE}

The audience is the object of the communicator. Most of the audiences of Focus On are Gao Xiaosong's previous followers, who can be divided into loyal audience and marginal audience.

\section{A. Loyal Audience}

Most of the loyal audiences of Focus On are those who have been following Gao Xiaosong since the very beginning,

continuous creativity, communication ability and influence ability of original differentiated content are the key to its 
or the audience attracted by Xiao Song Pedia and Let's Talk. They followed Gao Xiaosong from one program to another, and are typically loyal audience. These audiences expressed great interest and appreciation for Gao Xiaosong's life experience, knowledge, talent, appearance and experience, and has been following Gao Xiaosong's moves.

\section{B. Marginal Audience}

There is another kind of communication audience, which does not belong to fans and is not completely indifferent, only when they are interested in a certain point, they will pay attention to it. They have a certain curiosity about something unknown, curious, or rare, or they want to get out of their comfort zone and explore what other people's world is like. This kind of audience wandering between fans and passersby belongs to marginal audience. These marginal audience include: audience who like the time when Gao Xiaosong grew up and are willing to listen to his stories of those times; audience who want to be literary youth; audience who grew up in the same era as Gao Xiaosong, and envy his life experience; the idealists who yearn for beautiful things and hope to get inspiration and comfort from Gao Xiaosong to get rid of the plight they are facing; and audience that likes Gao Xiaosong's working style and unruly life attitude.

\section{THE EFFECT OF COMMUNICATION}

The communication effect is that the information of the communicator is delivered to the audience through the media, and then the audience is prompted to change their behaviors and ideas. Since this study is based on the Focus On of Dragonfly FM and takes knowledge web celebrity, Gao Xiaosong, as the research object, it is difficult to find the direct transmission data of its communication effect. However, from the perspective of user engagement and willingness to pay, Focus On built around the super IP, Gao Xiaosong, has achieved the expected communication effect.

First of all, from the perspective of user engagement, many users of Focus On are attracted by Gao Xiaosong. An overview of the audio market and video market shows that Gao Xiaosong has done columns in iQIYI, YOUKU and other video platforms in a personal form, and then developed his own business in the audio market. Video market and audio market users overlap, greatly enhance Gao Xiaosong's personal user engagement. This paid audio program has the feature of audio broadcasting, allowing users to directly talk to Gao, thereby strengthening the user's loyalty to Gao.

Second, in terms of willingness to pay, Gao Xiaosong has long called Focus On "conversations". Compared with the serious expression of traditional content, Focus On is loose, casual and informal, and the content is more relaxed and humorous, but also full of knowledge. Such affability, akin to Roosevelt's fireside chats, often dazzled users, who felt they were chatting alone with Gao Xiaosong, where knowledge and information could be acquired, prompting them to pay again. When users start to get used to paying for something, the payment model is more conducive to enhancing the stickiness of users. More importantly, when users subscribe to Focus On, they also gain the access to other paid programs with Dragonfly FM. Paid audio can not only help users form the habit of opening the APP in a fixed cycle, maintain the stickiness of users to the audio APP, but also enhance the audience's willingness to pay for the audio APP and audio market.

It can be said that Gao Xiaosong, in Focus On, uses his knowledge system to build a set of paid content products different from the past to achieve a win-win outcome in personal brand and business.

\section{CONCLUSION}

With the update of smart devices, mobile audio can cross the limitation of time and space and shorten the distance between knowledge web celebrity and the audience. Audio can make users feel friendly, as if someone is talking to you in the ear, and audience happiness will be greatly increased, thereby creating a favorable impression of the program. This paid audio program, Focus On, absorbed the characteristics of audio broadcasting, and captured the attention of users by using this feature, so that users can directly talk with Gao Xiaosong, and Gao Xiaosong, the content communicator, can give play to the maximum resultant force among various communication elements on the communication platform.

\section{REFERENCES}

[1] Ma Mengjuan. Research on the Propogation of Knowledge Web Celebrity Ritual in the Era of "Live Broadcast $+"$ [D]. Anhui University, 2018. (in Chinese)

[2] MBA Library. Knowledge Web Celebrity [OL]. 2018-08-21. (in Chinese)

[3] Yu Guoming, Guo Chaokai. Online Knowledge Payment: Main Types, Morphological Structure and Development Model [J]. Editors Monthly, 2017(5): 6-11. (in Chinese)

[4] CNNIC released the 38th Statistical Report on the Development of China's Internet [OL]. 2016-08-03.

[5] MBA Library - Super IP [OL].2018-09-06. (in Chinese)

[6] Tang Ying. Dragonfly FM: The Scene Revolution of Sound Economy under Super IP Vision [J]. Research on Transmission Competence, 2018,2(17):59. (in Chinese)

[7] CNNIC released the 43rd Statistical Report on the Development of China's Internet [OL]. 2019-02-28.

[8] Zhu Weijue. A Non-economical Unscrambling of 'Capital' — Pierre Bourdieu's Concept of 'Historical Capital' [J]. Journal of Social Sciences, 2005(06):117-123. (in Chinese)

[9] Rogers, Everett [M]. (1994). A History of Communication Study: A Biographical Approach. NY: The Free Press.

[10] Feminist Jurisprudence [J]. Women and the Law: Wm. S. Hein Publishing, 1999, 370.

[11] SamarMouakket. Factors Influencing Continuance Intention to Use Social Network Sites:The Facebookcase [J]. Computers in HumanBehavior, 2015,53.

[12] Zou Bohan, Luo Hao. Knowledge Payment - A Knowledge Transmission Mode with Openness, Sharing and Payment as the Core [J]. New Media Research, 2017,3(11):110-112+132. (in Chinese)

[13] Wang Fu. Study on We Media Marketing Model from the Perspective of Web Celebrity Economy - Taking Logic Thinking as an Example [J]. Heilongjiang Foreign Economic Relations and Trade, 2017(07): 83-84+102. (in Chinese)

[14] Chen Beilei. Tara Himalaya: Knowledge Web Celebrity Incubator [J]. China Entrepreneur, 2018 (12): 91-93. (in Chinese) 